\title{
Investment Risk Measurement for Agricultural ETF
}

\author{
Andrii Kaminskyi \\ Department of Economic Cybernetics \\ Taras Shevchenko National University of Kyiv \\ Kyiv, Ukraine \\ e-mail: kaminskyi.andrey@gmail.com
}

\author{
Maryna Nehrey \\ Department of Economic Cybernetics \\ National University of Life and Environmental Sciences of \\ Ukraine \\ Kyiv, Ukraine \\ e-mail: maryna.nehrey@gmail.com
}

\begin{abstract}
The aim of the paper is to measure the risk of agriculture ETF in the context of portfolio investment. The agriculture ETF be a special investment class which indicates relatively low correlated returns with traditional investment classes. One of the reasons of this is impact of weather and crop yield on return of such ETF which others types of ETF lacked. A sample of a basic agriculture ETF has been formed, which includes as diversified funds as a specific commodity ETF that targets to some agricultural product. To achieve the goal, we conducted a risk assessment using different approaches. Approaches based on variability conception and losses in negative situations are used. Special focus was applied for sensitivity analysis, which includes the Economic Policy Uncertainty index, and correlation analysis. Main results of research show differences in risk estimation for different types of agriculture ETF in comparison with ETF of traditional assets. Sensitivity analysis indicates high level of nonsystematic risk. Obtained results can be applied for creating "agriculture part" of a widely diversified investment portfolio.
\end{abstract}

Keywords - Exchange Trade Funds, portfolio management, agriculture, investment, risk measurement

\section{INTRODUCTION}

The formation, structuring and management of an investment portfolio is an integral part of modern institutional investors functioning. In the classic version, the creation of a portfolio involves the choice of asset classes (strategic allocation) and the technique of filling the components of each class. This approach is based on various classes of traditional investment assets of stocks and bonds. The emergence of Exchange Trade Funds (ETF) in the early $1990 \mathrm{~s}$ and their intensive development expanded the portfolio management tools in two ways. First, the essence of the ETF design has allowed expanding the asset classes that can be used in the portfolios. In this regard, it is possible to use ETF connected with non-traditional investments (commodities, gold, private equity, and many others). Such possibilities essentially expand the diversification approach. As a rule, non-traditional investments indicate lower correlation level with other. Secondly, an ETF makes it easy to assess the risk and return of the entire portfolio based on their characteristics. In addition, to some extent, with this approach, the task of filling the class with assets can be removed, because ETF diversified funds can be used. The task of portfolio investment, in fact, is more reduced to a strategic allocation.

The aim of this paper is to measure the "risk-return correspondence" for agricultural ETF (and ETN). This class is part of the commodities ETF and has its own distinctive features. The first distinctive aspect is that the prices of agricultural production are determined both by market factors (demand in the first place) and the corp yield (production) of a particular agricultural product. The dependence on yield generates an additional level of lack of correlation of such ETFs with other investment assets, which can be used in investment portfolio forming procedures. The second distinctive feature of the agricultural ETF is their structuring into ETFs associated with one agricultural product (for example, wheat, rice, livestock, and others), and associated with a specific fund diversified through different agricultural products. Understanding the difference in "riskreturn correspondence" in this context will allow a better justification for their using in the portfolio structure.

\section{MATERIALS AND Methods}

\section{A. Risk measurement conception}

Risk measurement in the frameworks of portfolio investment can be structured into two blocks. The first block is a risk assessment of an investment asset, considered separately. The second block focuses on assessing the relationship between asset returns and risk through diversification.

The first block of risk supposes to introduce mapping $\mu$ which each return of investment asset $R$ (interpreting as random variable) correspond some non-negative number $\mu(R) \square[0 ;+\infty]$. The return of investment asset (in this paper - ETF) over a period of time $[t-1 ; t]$ will be expressed through the formula:

$$
R_{t, t+1}=\left(P_{t+1}-P_{t}\right) / P_{t}
$$

where $P_{t}$ and $P_{t+1}$ prices of ETF in USD at times $t$ and $t+1$ correspondingly. $R_{t, t+1}$ will be a random variable, because the future price $P_{t+1}$ is unknown. Thereafter $R$ which reflect return through the time is also random variable. Mapping $\mu$ which corresponds to some rules interpret as risk measuring.

\section{B. Investment risk measures approaches}

There are many measures of investment risk present which formalise in mapping $\mu$ different logic of risk interpreting [1]. In our research, we have divided risk measuring into three conceptual approaches:

- Variability approach. Such an approach is based on the measurement of return. This approach goes back to the papers of H. Markowitz [2] and underlies the models of modern portfolio theory. Critiques of it 
using in the non-transparency connection between variability indicators and real losses.

- Losses in a negative situation. This more practical and regulative approach. It focuses on measuring possible losses and fullfill capital requirements.

- Sensitivity approach. According to such an approach, the risk is measured as the rate of response for occurring some factors.

Each of the abovementioned approaches had their pros and cons. Our point of that investment risk should be estimated by all these conceptual approaches. It provides multifaceted understanding of investment risk.

The logic of risk measuring leads to properties which reflect "natural properties" of risk. Trying to understand the essence of properties which should be represented in risk measure was formulated in [3]. Authors created the notion of coherent risk measure. Risk measure is coherent if satisfying following properties (axioms):

Axiom 1. Sub-additivity. For all random values presenting asset`s returns $R_{1}$ and $R_{2}$ we have

$$
\boldsymbol{\mu}\left(R_{1}+R_{2}\right) \leq \boldsymbol{\mu}\left(R_{1}\right)+\boldsymbol{\mu}\left(R_{2}\right)
$$

Axiom 2. Positive Homogeneity. For all $\mathrm{R}$ and for all $\lambda \geq 0$, we have

$$
\boldsymbol{\mu}(\lambda R)=\lambda \boldsymbol{\mu}(R)
$$

Axiom 3. Monotonicity: If $R_{1} \geq R_{2}$ for all possible cases then

$$
\boldsymbol{\mu}\left(R_{1}\right) \leq \boldsymbol{\mu}\left(R_{2}\right) .
$$

Axiom 4. Translation Invariance. For all $\mathrm{R}$ and for all $\alpha \geq 0$ which interpret as risk-free asset, we have

$$
\boldsymbol{\mu}(R+\alpha)=\boldsymbol{\mu}(R)-\alpha .
$$

Examples of coherent risk measures are Conditional Value-at-Risk (considered introduced below) [4] and T.Fischer measure [5]. It is necessary to note, that presented approach for coherency is not unique. Other approaches of coherency are considered in Kaminskyi [6].

The second block of risk measurement in the portfolio aspect corresponds to estimate interrelations of returns of different asset classes. It can be estimated as average correlation, reducing the value of chosen risk measure for a naïve diversified portfolio or risk value for the portfolio with minimum risk.

Below we try to realize these ideas for agricultural ETF.

\section{RESULTS AND DISCUSSION}

\section{A. Literature review}

There has been a lot of academic studies that have addressed agricultural investment and agriculture assets. The last of them are [7] - [13].

Martin and Clapp [14] investigated the relation between agriculture, finance, and the state. In [15] the authors analyzed the relation between the notional value of commodity futures contracts and expected returns on futures contracts.
ETFs as financial instruments investigated in [16], [17]. A. Petajisto proposed a method for ETFs mispricings detection [18].

\section{B. Sample of agricaltural ETF}

Our sample of agricultural ETF was created on the base of capitalization level of such financial instrument which traded in the USA which are currently tagged by ETF Database. It is necessary to note that we use term ETF in extend sense which include both instruments which tracking indices: ETF and ETN. Of course, we pay attention for the differences between these instruments, but our main focus for the conceptual essence of tracking indices, after that we did not differentiate ETF and ETN in our paper and use one term ETF.

Agriculture ETFs invest in agriculture commodities including sugar, corn, soybeans, coffee, wheat and other. It can be single commodity fund or diversified fund. We have formed sample (12 components) based on total assets volume by following ETF (ETN).

CORN. This ETF correspond to Teucrium Corn Fund which tracks an index of corn futures contracts.

COW. This ETN offers an opportunity for investors to gain exposure to hogs and cattle iShares Global Agriculture Index ETF.

DBA. This ETF correspond to diversified basket of various agricultural natural resources.

FUD. This is ETN, associated with futures-based index that measures the collateralized returns from a basket of 11 futures contracts from the agricultural and livestock sectors.

FUE. This ETN is linked to an index that is designed as a benchmark for the biofuels sector.

JJSF. This is ETN which connected with sugar futures.

NIB. This ETN offers exposure to cocoa futures.

RJA. RJA ETN tracks Rogers International Commodity Index-Agriculture which is consumption-based index of agricultural commodities.

UAG. Exchange-traded note which offers exposure to a number of agricultural commodities, including corn, soybeans, wheat, coffee, cocoa, and other natural resources.

CANE. This ETF offering exposure to the commodity of sugar.

SOYB. This ETF invests in soybean futures contracts.

WEAT. This ETF offers exposure to wheat futures contracts.

The following ETFs were chosen for comparison agricultural ETF with traditional assets ETF.

SPDR's SPY to model the large-cap public equities, it tracks the Standard \& Poor's 500 and is the oldest and largest of all ETFs.

SPDR's MDY that tracks the Standard \& Poor's 400 to model the mid-cap equities, while being smaller than iShares IJH it has about the same turnover but offers a longer time series. 
iShares IJR to model the small-cap companies, it tracks the Standard \& Poor's 600 index and is much larger and liquid than the corresponding SPDR fund SLY.

iShares IEF to model a balanced portfolio of Treasury bonds, the choice of this particular government bond fund is motivated by its duration 7.6 years that is comparable to the duration of other bond funds analyzed in this paper.

iShares LQD to model a balanced portfolio of investment-grade corporate bonds, it's one of the oldest bond ETFs and its duration (8.5 years) is approximately the same as for the IEF fund mentioned above, so we can contrast government and corporate bonds.

iShares TIP to model inflation-linked bonds, an asset class that should have quite a distinct characteristics, however its duration (7.6 years) aligned to LQD and IEF.

\section{The variability approach to risk measurement}

The applying variability approach to risk measurement of agriculture ETF makes it possible to identify the specificities (Table I).

TABLE I. STATISTICAL ANALISYS FOR RISK MEASURES

\begin{tabular}{|l|l|l|l|l|l|l|}
\hline ETF & min & max & mean & std.dev & skewness & kurtosis \\
\hline \multicolumn{7}{|c|}{ Agricultural ETF } \\
\hline CORN & $-0,206$ & 0,210 & $-0,003$ & 0,066 & 0,492 & 1,051 \\
\hline COW & $-0,111$ & 0,116 & 0,009 & 0,038 & 0,004 & 0,494 \\
\hline DBA & $-0,130$ & 0,112 & $-0,003$ & 0,038 & 0,371 & 1,577 \\
\hline FUD & $-0,157$ & 0,165 & 0,000 & 0,049 & 0,480 & 1,444 \\
\hline FUE & $-0,198$ & 0,365 & 0,002 & 0,079 & 0,917 & 3,507 \\
\hline JJSF & $-0,120$ & 0,135 & 0,014 & 0,049 & $-0,045$ & 0,181 \\
\hline NIB & $-0,202$ & 0,180 & $-0,001$ & 0,080 & $-0,347$ & $-0,528$ \\
\hline RJA & $-0,161$ & 0,143 & $-0,001$ & 0,047 & 0,289 & 1,628 \\
\hline UAG & $-0,175$ & 0,147 & 0,000 & 0,056 & 0,268 & 0,895 \\
\hline CANE & $-0,140$ & 0,155 & $-0,012$ & 0,058 & 0,452 & $-0,124$ \\
\hline SOYB & $-0,128$ & 0,131 & $-0,002$ & 0,051 & 0,252 & $-0,123$ \\
\hline WEAT & $-0,187$ & 0,228 & $-0,013$ & 0,069 & 0,510 & 1,044 \\
\hline EPU & $-0,474$ & 0,982 & 0,023 & 0,219 & 1,080 & 3,429 \\
\hline SPY & $-0,093$ & 0,109 & 0,010 & 0,036 & $-0,260$ & 0,448 \\
\hline MDY & $-0,117$ & 0,136 & 0,010 & 0,043 & $-0,278$ & 0,938 \\
\hline IJR & $-0,126$ & 0,149 & 0,011 & 0,047 & $-0,203$ & 0,653 \\
\hline IEF & $-0,044$ & 0,044 & 0,001 & 0,016 & 0,133 & 0,383 \\
\hline LQD & $-0,036$ & 0,038 & 0,001 & 0,015 & $-0,083$ & 0,022 \\
\hline & $-0,044$ & 0,032 & 0,001 & 0,013 & $-0,396$ & 1,332 \\
\hline EIP & \multicolumn{7}{|c|}{ ETF of traditional assets } & & \\
\hline
\end{tabular}

First of all, range as a risk measure which defines as max-min indicates higher values than traditional assets. The average value of ranges for agro ETF approximately four times more than averages of ETF connected with indexes of bonds and approximately 1,4 times more than this value for stock indices. So, from this point of view, agro ETF is riskier. The similar conclusion can be formed on the base of analysis Fig.1 where presenting classical Markowitz riskreturn correspondence.

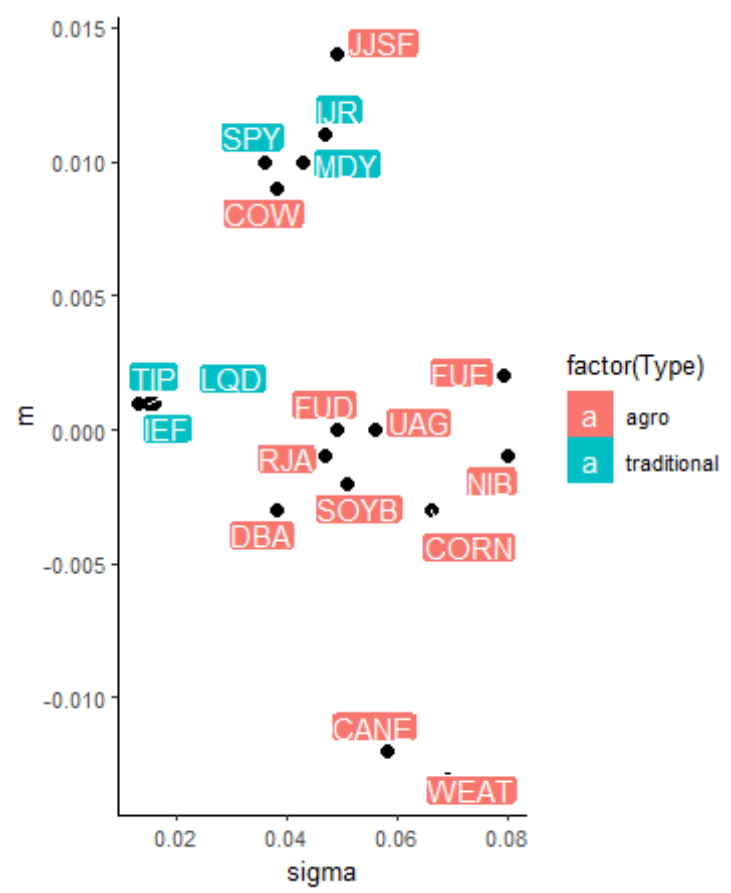

Fig. 1. ETFs risk-return correspondence

It is interesting results we can identify by analysis of skewness, which indicates divergence from symmetry. Negative skewness indicates a long left tail of the distribution, or the possibility of larger losses than profits. Positive skewness is a desirable characteristic for risk-averse investors. The motivation of that is based on the expected utility theory (see e.g. Scott and Horvath (1980)). From this point of view, agro ETFs are more desirable to risk-averse investors the traditional which have negative skewness. Such risk measure as kurtosis can be considered as measure of risk associated with heavy tails. Agro ETFs illustrate higher values of kurtosis then ETFs for traditional assets. So, conclusion from the variability approach for risk measurement can be done as more volatile segment with positive skewness.

\section{Risk measurement as losses in negative situation}

This conceptual approach is based on considering measures relating to the interpretation of "negative situation" for the investor. The most popular in this group is Value-atRisk (VaR), which presents a quantile corresponding to some level of safety (it maybe $95 \%, 99 \%$ or $99.9 \%$ ). The logic of $\mathrm{VaR}$ is based on risk covering. If, for example, $\mathrm{VaR}$ orients for $95 \%$, then $5 \%$ biggest losses will throw off. VaR will cover maximum losses at the framework of $95 \%$ possibilities. Risk measure Conditional Value-at-Risk $(\mathrm{CVaR})$ is based on a generalization of $\mathrm{VaR}$. This is the conditional mathematical expectation of losses which higher than VaR. 
Considering risk measuring for agro ETF we find that Value-at-Risk and Conditional Value-at-Risk is higher than similar values for traditional assets but not so much. It is an interesting conclusion that ratio $\mathrm{CVaR} / \mathrm{VaR}$ for agro ETFs is a good indicator of the distinction of risk.

TABLE II. ETFS VAR, CVAR

\begin{tabular}{|l|c|c|}
\hline \multicolumn{1}{|c|}{$\mathbf{E T F}$} & $\mathbf{V a R}(\mathbf{p = 0 , 9 5})$ & $\mathbf{C V a R}(\mathbf{p}=\mathbf{0 , 9 5})$ \\
\hline CORN & $-0,0999$ & $-0,1253$ \\
\hline COW & $-0,0525$ & $-0,0699$ \\
\hline DBA & $-0,0591$ & $-0,0791$ \\
\hline FUD & $-0,0722$ & $-0,0965$ \\
\hline FUE & $-0,0997$ & $-0,1463$ \\
\hline JJSF & $-0,0663$ & $-0,0922$ \\
\hline NIB & $-0,1396$ & $-0,1634$ \\
\hline RJA & $-0,0722$ & $-0,0980$ \\
\hline UAG & $-0,0855$ & $-0,1151$ \\
\hline CANE & $-0,0990$ & $-0,1101$ \\
\hline SOYB & $-0,0829$ & $-0,1015$ \\
\hline WEAT & $-0,1138$ & $-0,1436$ \\
\hline SPY & $-0,2476$ & $-0,3482$ \\
\hline MDY & $-0,0619$ & $-0,0894$ \\
\hline IJR & $-0,0684$ & $-0,0964$ \\
\hline IEF & $-0,0239$ & $-0,0320$ \\
\hline LQD & $-0,0239$ & $-0,0314$ \\
\hline TIP & $-0,0212$ & $-0,0285$ \\
\hline
\end{tabular}

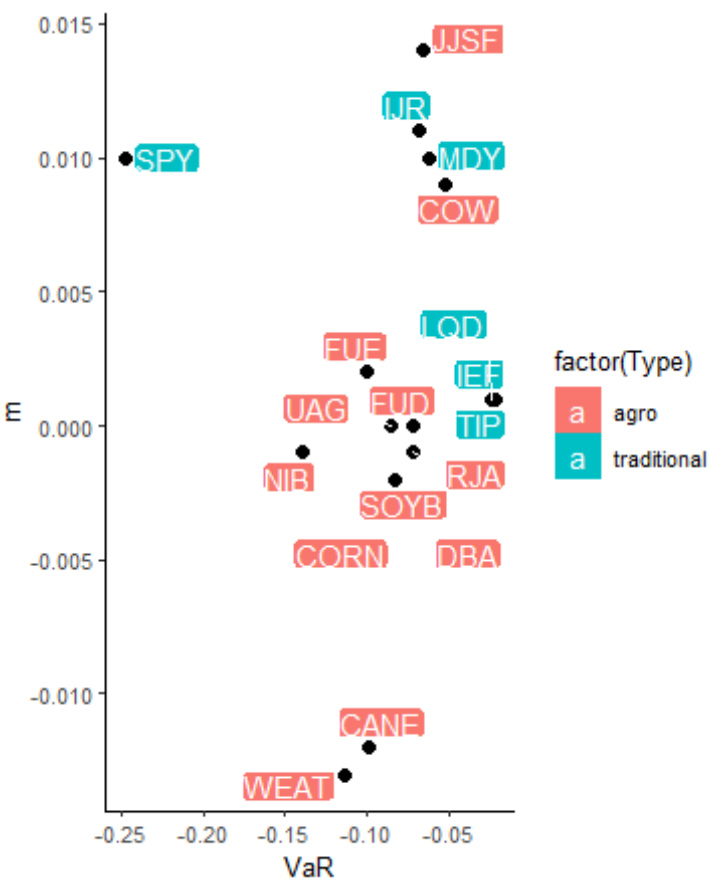

Fig. 2. ETFs Value-at-Risk
The ratio $\mathrm{CVaR} / \mathrm{VaR}$ characterizes correspondence between "catastrophic" losses and maximal losses at the frameworks of $95 \%$ safety level.

Our consideration shows that ratio belongs to the interval [1.11; 1.47]. Such an interval for a sample of traditional assets is $[1.31 ; 1.44]$. The average value for agro ETF is lower than for such value for a sample of traditional assets. The correspondence between ETF for traditional assets and agricultural ETF is exemplified by Figure 2 below. Agricultural ETF are dominated by ETF traditional ETF by bith criteria (minimisation $\mathrm{VaR}$ and maximisation return).

\section{E. Risk measurement based on sensitivity analysis}

Risk measurement at the frameworks of sensitivity analysis provides an opportunity to understand the role of systematic and non-systematic risks. We have chosen for sensitivity analysis two systematic factors. The first factor is the return of the S\&P 500, which present by corresponding ETF (SPY). The logic of this choice lies in interpreting the S\&P 500 as a factor of the stock market. And analysis should provide an answer to the question: How the stock market as a whole affect to the return of ETF?

The second factor which we have chosen is the Economic Policy Uncertainty index (EPU index). This index focus on the formalization of appearance information in the economy. It includes 3 parts. The first part includes a component which quantifies newspapers coverage of different political uncertainties. A second component reflects the number of federal tax code provisions set to expire in future years. The third component uses disagreement among economic forecasters as a proxy for uncertainty. It is possible to consider such index at the context of E.Fama ideas about information efficiency. The index is a quantitative presentation of some information event of the market. The basic idea was used for verification: Does agro ETFs sensitive for new information? The answer for this question: Not. Their returns have not essential dependency with information index EPU.

TABLE III. REGRESSION ANALISYS

\begin{tabular}{|l|c|c|c|c|c|}
\hline ETF & Intercept & $\begin{array}{c}\text { SPY beta } \\
\text { coefficient }\end{array}$ & $\begin{array}{c}\text { EPU beta } \\
\text { coefficient }\end{array}$ & $\mathbf{R}^{2}$ & p-value \\
\hline CORN & $-0,002$ & 0,09 & 0,014 & 0,01 & 0,74 \\
\hline COW & 0,002 & 0,69 & $-0,009$ & 0,42 & $1,11 \mathrm{e}^{-13}$ \\
\hline DBA & $-0,006$ & 0,31 & 0,026 & 0,07 & 0,007 \\
\hline FUD & $-0,004$ & 0,42 & 0,035 & 0,08 & 0,004 \\
\hline FUE & $-0,004$ & 0,53 & 0,052 & 0,05 & 0,03192 \\
\hline JJSF & 0,007 & 0,53 & 0,033 & 0,13 & 0,000216 \\
\hline NIB & $-0,001$ & 0,18 & $-0,049$ & 0,01 & 0,2107 \\
\hline RJA & $-0,006$ & 0,51 & 0,026 & 0,13 & 0,00029 \\
\hline UAG & $-0,006$ & 0,57 & 0,048 & 0,13 & 0,00031 \\
\hline CANE & $-0,016$ & 0,32 & 0,026 & 0,01 & 0,2242 \\
\hline SOYB & $-0,006$ & 0,29 & 0,035 & 0,02 & 0,1344 \\
\hline WEAT & $-0,014$ & 0,14 & 0,015 & 0,01 & 0,79 \\
\hline
\end{tabular}


The sensitive analysis was realized at the frameworks of abovementioned two factors regressions. The main result is very low R-squared indicators. The economic consequence of this is the domination of nonsystematic risks in returns of agro ETFs.

\section{F. Correlation analysis}

Correlation analysis was provided as inside the sample of agriculture ETF as between traditional assets. It is interesting that agriculture ETFs indicate very low correlation not only with traditional assets but inside sample group (Table IV). This leads to consideration portfolio construction directly through agricultural ETF and through all types of ETF.

TABLE IV. CORRELATION ANALYSIS

\begin{tabular}{|c|c|c|}
\hline $\begin{array}{c}\text { Average } \\
\text { correlation } \\
\text { between } \\
\text { sample } \\
\text { agriculture } \\
\text { ETFs }\end{array}$ & $\begin{array}{c}\text { Average correlation } \\
\text { between sample } \\
\text { agriculture ETFs and } \\
\text { sample of ETF } \\
\text { stocks of traditional } \\
\text { asset }\end{array}$ & $\begin{array}{c}\text { Average correlation } \\
\text { between sample } \\
\text { agriculture ETFs and } \\
\text { sample of ETF } \\
\text { bonds of traditional } \\
\text { asset }\end{array}$ \\
\hline 0,26 & 0,14 & 0,02 \\
\hline
\end{tabular}

For comparison average correlation between sample ETF stocks of traditional asset is 0,9 . So, traditional assets are more interdependent and considered ETFs are more independent.

We think that so low correlation can be explain by affecting on these ETF real prices for agricultural products. Not by supply and demand as it appearance at the stock market.

\section{CONCLUSION}

Portfolio management has new tools for strategic allocation investments between classes. This tool arises from essence of Exchange Trade Funds. ETFs can represent different asset classes which previously cannot be included efficiently to the portfolios. One of such class is agriculture ETFs. The results of complex risk measurement indicate some specificities of this class. First of all, risk level higher than risk of traditional assets. But not so much. It is possible to consider this class as moderate level of risk. The characteristic features of risk of this class are: 1) positive skewness. The agro ETFs which linked with single product illustrates higher positive values of skewness return. 2) lower than for traditional assets correspondence CVaR/VaR. The economic explanation is indicates lower left tail of distribution of return and 3) domination of non-systematic risk. Correlation analysis shows that this class has low correlation inside class and low correlations with classes of traditional asset classes. EPU do not affect for return of agro ETF.

The using of agricultural ETF should involve consideration type of ETF. Thus, "mono" ETF, which correspond to some concrete agricultural product has more risk than diversified ETF. As example, kurtosis of returns of such ETF higher in 1,13. The average of coefficient of variations is higher more than 1,26 times than coefficient of variations for diversified ETF.

The basic economic logic of apply these results in portfolio management is combination traditional investment classes with agriculture ETF. Such combination will rise diversification effect from non-correlation properties.

Further investigation may include analysis differences in types of probability of distribution functions for traditional assets and agro ETF

\section{REFERENCES}

[1] Giorgio P. Szegö, ed. Risk measures for the 21st century. Vol. 1. New York: Wiley, 2004.

[2] H. Markowitz, Portfolio Selection: Efficient Diversification of Investment, John Wiley \& Sons Ltd, 1959

[3] P. Artzner, F. Delbaen, J. M. Eber, and D. Heath, "Coherent measures of risk", Mathematical finance, vol. 9, no. 3, pp. 203-228, 1999.

[4] R. Rockafellar, S. Uryasev, "Optimization of conditional Value-AtRisk", The Journal of Risk, vol. 2, no. 3, pp. 21-41, 2000.

[5] T. Fischer, "Risk capital allocation by coherent risk measures based on one-sided moments", Insurance: Mathematics and Economics, vol. 32, pp. 135-146, 2003.

[6] A. Kaminskyi, Financial Risk Modeling. Kyiv: Kyiv National Taras Shevchenko University (in Ukrainian), 2007.

[7] J. Clapp, "Responsibility to the rescue? Governing private financial investment in global agriculture", Agriculture and human values, vol. 34, no. 1, pp. 223-235, 2017.

[8] P. Andreasson, S. Bekiros, D. K. Nguyen, and G. S. Uddin, "Impact of speculation and economic uncertainty on commodity markets," International review of financial analysis, vol. 43, pp. 115-127, 2016.

[9] R. Valdes, What drives the regional integration of agribusiness stocks? Evidence in worldwide perspective, 2017.

[10] A.Rasool, Investing in Agribusiness Stocks and Farmland: A Boom or Bust Analysis, 2018.

[11] M. Johnson, B. Malcolm, and I. O'Connor, "The Role of Agribusiness Assets in Investment Portfolios," Australasian Agribusiness Review, vol. 14, 2006. [Online]. Available: https://www.researchgate.net/publication/241808104 The Role of Agribusiness Assets in Investment Portfolios. Accessed on: 29 June 2019.

[12] B. M. Clark, J. D. Detre, J. D'Antoni, and H. Zapata. "The role of an agribusiness index in a modern portfolio," Agricultural Finance Review, vol. 72, no. 3, pp. 362-380, 2012.

[13] S. Chen, W. W. Wilson, R. Larsen, and B. Dahl, "Investing in Agriculture as an Asset Class," Agribusiness, vol. 31, pp. 353-371, 2015 .

[14] S. J. Martin, J. Clapp, "Finance for agriculture or agriculture for finance?" Journal of Agrarian Change, vol. 15, no. 4, pp. 549-559, 2015.

[15] J. D. Hamilton, J. C. Wu, "Effects of index- fund investing on commodity futures prices", International economic review, vol. 56, no. 1, pp. 187-205, 2015.

[16] G. R. Jensen, and M. M. Jeffrey, "Commodities as an Investment." pp. 1-33, 2011.

[17] H. R. Stoll, and R. E. Whaley, "Commodity Index Investing and Commodity Futures Prices", Journal of Applied Finance (Formerly Financial Practice and Education), vol. 20, no. 1, 2010. [Online]. Available: https://www.cftc.gov/sites/default/files/idc/groups/public/ @ swaps/documents/file/plstudy_45_hsrw.pdf. Accessed on: 29 June 2019.

[18] A. Petajisto, "Inefficiencies in the pricing of exchange-traded funds", Financial Analysts Journal, vol. 73, no. 1, pp. 24-54, 2017. 